\title{
Haemolytic anaemia in an HIV-infected patient with severe falciparum malaria after treatment with oral artemether-lumefantrine
}

\author{
Angela Corpolongo*, Pasquale De Nardo, Piero Ghirga, Elisa Gentilotti, Rita Bellagamba, Chiara Tommasi, \\ Maria Grazia Paglia, Emanuele Nicastri and Pasquale Narciso
}

\begin{abstract}
Intravenous (i.v.) artesunate is now the recommended first-line treatment of severe falciparum malaria in adults and children by WHO guidelines. Nevertheless, several cases of haemolytic anaemia due to i.v. artesunate treatment have been reported. This paper describes the case of an HIV-infected patient with severe falciparum malaria who was diagnosed with haemolytic anaemia after treatment with oral artemether-lumefantrine.

The patient presented with fever, headache, and arthromyalgia after returning from Central African Republic where he had been working. The blood examination revealed acute renal failure, thrombocytopaenia and hypoxia. Blood for malaria parasites indicated hyperparasitaemia (6\%) and Plasmodium falciparum infection was confirmed by nested-PCR. Severe malaria according to the laboratory WHO criteria was diagnosed. A treatment with quinine and doxycycline for the first 12 hours was initially administered, followed by arthemeter/lumefantrine (Riamet ${ }^{\circledR}$ ) for a further three days. At day 10, a diagnosis of severe haemolytic anaemia was made ( $\mathrm{Hb} 6.9 \mathrm{~g} / \mathrm{dl}, \mathrm{LDH} 2071 \mathrm{U} / \mathrm{l})$. Hereditary and autoimmune disorders and other infections were excluded through bone marrow aspiration, total body TC scan and a wide panel of molecular and serologic assays. The patient was treated by transfusion of six units of packed blood red cell. He was discharged after complete remission at day 25. At present, the patient is in a good clinical condition and there is no evidence of haemolytic anaemia recurrence.

This is the first report of haemolytic anaemia probably associated with oral artemether/lumefantrine. Further research is warranted to better define the adverse events occurring during combination therapy with artemisinin derivatives.
\end{abstract}

Keywords: Severe malaria, Artemisinin-based combination therapy (ACT), Haemolytic anaemia, Drugs and haemolytic anaemia

\section{Background}

Artemisinins were discovered in 1971 from a herb, Artemisia annua, known in the past for their activity against intermittent fever [1]. Now, artemisinin and its derivatives have become essential components of artemisinin-based combination therapy (ACT) [2]. Intravenous (i.v.) artesunate is the recommended first-line treatment of severe falciparum malaria in adults and children, including cerebral malaria, because they produce rapid parasite/fever clearance, show fewer adverse

\footnotetext{
* Correspondence: angela.corpolongo@inmi.it

National Institute for Infectious Diseases "Lazzaro Spallanzani", Via Portuense 292, 00149 Rome, Italy
}

\section{Biomed Central

(c) 2012 Corpolongo et al; licensee BioMed Central Ltd. This is an Open Access article distributed under the terms of the Creative Commons Attribution License (http://creativecommons.org/licenses/by/2.0), which permits unrestricted use, distribution, and reproduction in any medium, provided the original work is properly cited. of less resistance $[3,4]$. The World Health Organization's (WHO) up-to-date guidelines recommend artesunate as the treatment of choice for adults and children with severe malaria [5]. However, quinine is still the primary treatment for severe non-multidrug resistant Plasmodium falciparum malaria in Europe because i.v. artesunate is not registred for this indication. This paper describes the occurrence of a case of haemolytic anaemia in an HIV-infected patient with falciparum malaria treated with intravenous (i.v.) quinine and doxycycline for the first 12 hours and then with artemether-lumefantrine 


\section{Case report}

A 34-year-old man presented with a seven-day history of fever, headache, and arthromyalgia after returning from Central African Republic. He is Italian and he had been working for governmental and non-governmental organizations for several years. His past medical history included HIV infection known since October 2010 with no anti-retroviral treatment. At admission on 18 July, 2011, the physical examination revealed prostration, severe obesity (BMI 42), pallor, shallow tachypnoic breathing, and hepato-splenomegaly. Blood examinations showed acute renal failure (creatinine $3.29 \mathrm{mg} / \mathrm{dl}$ ), anaemia (Hb 7.4 g/dl), thrombocytopaenia (PLT 17000), glucose $88 \mathrm{mg} / \mathrm{dl}$, AST $108 \mathrm{U} / \mathrm{l}$, ALT $33 \mathrm{U} / \mathrm{l}$, bilirubin total $2.9 \mathrm{mg} / \mathrm{dl}$, bilirubin direct $1.5 \mathrm{mg} / \mathrm{dl}$, albumin $2,5 \mathrm{~g} / \mathrm{dl}$, G6PDH $16 \mathrm{U} / \mathrm{gHb}$, hypoxia and metabolic acidosis $(\mathrm{pH}$ 7.35, pO2 $62 \mathrm{mmHg}, \mathrm{HCO}^{-} 16.5 \mathrm{mmol} / \mathrm{l}$ ) (see Table 1). Polymerase Chain Reaction (PCR) and light microscopy on peripheral blood smear detected $P$. falciparum with a $6 \%$ parasitaemia. Severe malaria, according to WHO criteria (hyperparasitaemia, metabolic acidosis, renal impairment), was diagnosed [5].

The patient was initially treated with i.v. quinine loading dose $(20 \mathrm{mg} / \mathrm{kg}, 1500 \mathrm{mg})$ in combination with oral doxycycline $(100 \mathrm{mg})$ for the first 12 hours followed by oral fixed-dose co-formulated artemether/lumefantrine $\left(\right.$ Riamet $^{\circledR}$ ) for a further three days. At admission, the blood test detected moderate-severe anaemia ( $\mathrm{Hb} 7.4 \mathrm{~g} /$ $\mathrm{dl}$ and HCT 22\%) and a transfusion with one unit of packed red blood cells (RBC) was prescribed. Because of the persistence of the anaemia, the patient was transfused with a further RBC transfusion on day 4 ( $\mathrm{Hb} 6.7$ $\mathrm{g} / \mathrm{dl}$ and HCT 20\%). Parasite clearance time was 72 hours. Renal and pulmonary functions immediately improved but fever was still reported up to 28 July, when the diagnosis of severe haemolytic anaemia was performed (Hb $6.9 \mathrm{~g} / \mathrm{dl}$, haptoglobin $<7.19 \mathrm{mg} / \mathrm{dl}$, reticulocytes $4.8 \%$, LDH $2071 \mathrm{U} / \mathrm{l})$. The patient was transfused with an additional four packed blood transfusions on two different days.

Direct and indirect anti-globulin tests, cold agglutinin test, and auto-immune assays were all negative; PCR and antibody detection for chikungunya, dengue, serology for B19 Parvovirus, Leishmania species, Mycoplasma pneumoniae, Chlamydia pneumoniae, Mycobacterium tuberculosis complex, atypical mycobacteria, Salmonella typhi and paratyphi, Trypanosoma spp., Toxoplasma gondii, and Treponema pallidum were all negative; antigens of Cryptococcus neoformans were not detectable; PCR and peripheral blood smears for Plasmodium species were

Table 1 Laboratory data

\begin{tabular}{|c|c|c|c|c|c|c|}
\hline Test, unit & $\begin{array}{l}\text { Admission } \\
18 \text { July }\end{array}$ & $\begin{array}{l}\text { Day } 7 \\
25 \text { July }\end{array}$ & $\begin{array}{l}\text { Day } 10 \\
28 \text { July }\end{array}$ & Day 17 & $\begin{array}{l}\text { Day } 25 \\
12 \text { Aug }\end{array}$ & Normal values \\
\hline Glucose, g/dl & 88 & & 0.97 & & & $70-1.10$ \\
\hline Urea, g/l & 2.16 & & 0.33 & & & $0.10-0.50$ \\
\hline Creatinine, $\mathrm{mg} / \mathrm{dl}$ & 3.29 & & 0.65 & & & $0.5-1.4$ \\
\hline Potassium, $\mathrm{mEq} / \mathrm{l}$ & 3.5 & & 4.9 & & & $3.6-5.5$ \\
\hline Bilirubin total/direct, mg/dl & $2.9 / 1.5$ & $1.4 / 0.7$ & $1.6 / 0.6$ & $1.9 / 0.8$ & & $<1.2 / 0.3$ \\
\hline$\overline{A S T / A L T, U / I}$ & $108 / 33$ & $32 / 26$ & $40 / 23$ & & & $<40$ \\
\hline Erythrocytes, $10^{6} / \mathrm{mm} 3$ & 2.43 & 2.6 & 2.16 & 1.81 & 2.91 & $3.8-6.1$ \\
\hline Haemoglobin, g/dl & 7.4 & 8 & 6.9 & 5.9 & 9.6 & $12-18$ \\
\hline Haematocrit, \% & 22 & 24 & 20 & 18 & 29 & $36-52$ \\
\hline Reticulocytes \% & & & 4.8 & 8.2 & & $0.5-2.0$ \\
\hline Platelets, $10^{3} / \mathrm{mmc}$ & 17 & 114 & 127 & 98 & 152 & $80-400$ \\
\hline White blood cells, $10^{3} / \mathrm{mmc}$ & 5.1 & 6.7 & 5.3 & 2.6 & 3.5 & $4.3-10.8$ \\
\hline Neutrophils \% & 75.5 & 41.1 & 23.1 & 31.6 & 36.6 & $40-75$ \\
\hline Lymphocytes \% & 20 & 42.7 & 62 & 49 & 41.2 & $20-51$ \\
\hline CD4 cells/mmc (\%) & & $569(23.2)$ & & & & $(36-44)$ \\
\hline HIV-RNA, cp/ml & 161769 & & & & & \\
\hline Erythrocyte Sedimentation Rate, $\mathrm{mm} / \mathrm{hr}$ & 122 & & $>140$ & $>140$ & & $<15$ \\
\hline C-Reactive proteine $\mathrm{mg} / \mathrm{dl}$ & 21 & & & 4.7 & & $<0.6$ \\
\hline Thick and thin smears & Pos & Neg, day 3 & Neg & & & \\
\hline PCR for Plasmodium falciparum & Pos & Neg, day 3 & Neg & & & \\
\hline Parasitaemia & $6 \%$ & & & & & \\
\hline Coombs test direct/indirect & & & neg/neg & neg/neg & & \\
\hline
\end{tabular}


persistently negative. Bone marrow aspiration was negative for infectious agents and lympho-proliferative diseases. A total body CT scan reported splenomegaly. After significant improvement of his clinical condition, the patient was discharged on 12 August $(\mathrm{Hb} 9.6 \mathrm{~g} / \mathrm{dl})$. Five weeks after discharge, haemoglobin, haematocrit, reticulocytes count were all within normal values (see Table 1). The patient is now in good clinical condition and back to his daily working life with no evidence of haemolytic anaemia recurrence.

Written informed consent was obtained from the patient for publication of this case report.

\section{Discussion}

There are multiple causes of haemolytic anaemia, and the clinical presentation can differ depending on the etiology. Haemolysis may be extravascular due to autoimmune disorders or to hereditary spherocytosis, intravascular (e.g. associated to insertion of prosthetic cardiac valves, G6PDH deficiency, thrombotic thrombocytopenic purpura or disseminated intravascular coagulation), or intramedullary-related due to pernicious anaemia and thalassemia major. The haemolytic disorder can be hereditary as in case of G6PDH deficiency [6], haemoglobinopathies and RBC membrane abnormalities, or acquired, as in the case of immune disorders [7], exposure to toxic chemicals and drugs [8], paroxysmal nocturnal haemoglobinuria [9], traumatic and microangiopathic haemolysis, hypersplenism or infections [10].

In this report, hereditary and auto-immune disorders were excluded. Infectious agents other than malaria were searched for with a wide panel of molecular and serologic assays and through bone marrow examination. All the results were negative. CT scan and bone marrow analysis excluded lymphoproliferative disorders. Malaria was treated with i.v. quinine and doxycycline for the first 12 hours only, followed by Riamet ${ }^{\circledR}$ for 72 hours. At day 10 a diagnosis of severe haemolytic anaemia was established and it was treated by transfusion with six units of packed red blood cells. The duration of haemolysis was 15 days. The patient was discharged on 12 August after complete remission from severe malaria and haemolytic anaemia.

There are few cases described in literature of haemolytic anaemia during or after treatment with i.v. artesunate alone or combined with mefloquine. Yasouka et al reported the case of a Nigerian male with severe P. falciparum malaria initially treated with mefloquine. After one day of treatment, because of the worsening clinical condition of the patient and the increase of the parasitaemia, therapy with i.v. artesunate was initiated. Parasite clearance was obtained within 20 hours after the first administration of artesunate, but fever persisted for a further seven days and haemolytic anaemia was observed, requiring blood transfusion [11]. Yoshizawa et al described the case of a young woman with $P$. falciparum malaria who was successfully treated with i.v. artesunate, but showed worsening anaemia after artesunate administration [12]. Itoda et al observed severe haemolytic anaemia and jaundice on day 11 after i.v. artesunate administration in a 68-year-old Japanese woman affected by severe malaria [13]. Recently, Zoller et al reported a series of 25 travellers with severe malaria treated with i.v. artesunate. Among them, six patients developed haemolytic anaemia week after treatment possibily related to artesunate or had persistent signs of haemolytic activity until six weeks after the first dose of i.v. artesunate [14]. In this case series, patients with post-treatment haemolysis had received a higher cumulative dose of i.v. artesunate and were treated for longer periods.

This appears to the first reported case of haemolytic anaemia after treatment with oral fixed-dose co-formulated artemether/lumefantrine. The observation supports the hypothesis that haemolysis might occur as a consequence of artemether treatment. Efficacy and safety profiles of i.v. artesunate and ACT should be prospectively evaluated, and patients should be monitored for signs of haemolysis after parasitological cure.

\section{Authors' contributions}

AC, PDN, RB, EN collected and collated case information and details and obtained consent. All authors participated in drafting the medical part of the manuscript. MGP performed the PCR amplification and

immunohistochemistry. PG and EG were involved in literature search. All authors read and approved the final manuscript.

\section{Competing interests}

The authors declare that they have no competing interests.

Received: 30 December 2011 Accepted: 27 March 2012 Published: 27 March 2012

\section{References}

1. Kano S: Artemisinin-based combination therapies and their introduction in Japan. J Infect Chemother 2010, 16:375-382.

2. Hsu E: The history of qing hao in the Chinese materia medica. Trans $R$ Soc Trop Med Hyg 2006, 100:505-508.

3. Dondorp A, Nosten F, Stepniewska K, Day N, White N: South East Asian Quinine Artesunate Malaria Trial (SEAQUAMAT) group. Artesunate versus quinine for treatment of severe falciparum malaria: a randomised trial. Lancet 2005, 366:717-725.

4. Dondorp AM, Fanello Cl, Hendriksen IC, Gomes E, Seni A, Chhaganlal KD, Bojang K, Olaosebikan R, Anunobi N, Maitland K, Kivaya E, Agbenyega T, Nquah SB, Evans J, Gesase S, Kahabuka C, Mtove G, Nadjm B, Deen J, Mwanga-Amumpaire J, Nansumba M, Karema C, Umulisa N, Uwimana A, Mokuolu OA, Adedoyin OT, Johnson WB, Tshefu AK, Onyamboko MA, Sakulthaew T, Ngum WP, Silamut K, Stepniewska K, Woodrow CJ, Bethell D, Wills B, Oneko M, Peto TE, von Seidlein L, Day NP, White NJ, AQUAMAT group: Artesunate versus quinine in the treatment of severe falciparum malaria in African children (AQUAMAT): an open label, randomised trial. Lancet 2010, 376:1647-1657.

5. World Health Organization: Guidelines for the treatment of malaria. 2nd edition Geneva: The Organization; 2010.

6. Beutler E, Duparc S, G6PD Deficiency Working Group: Glucose-6-phosphate dehydrogenase deficiency and antimalarial drug development. Am J Trop Med Hyg 2007, 77:779-789. 
7. Zeerleder S: Autoimmune haemolytic anaemia - a practical guide to cope with a diagnostic and therapeutic challenge. Neth J Med 2011, 69:177-184.

8. Garratty G: Immune hemolytic anemia associated with drug therapy. Blood Rev 2010, 24:143-145.

9. Madkaikar M, Gupta M, Jijina F, Ghosh K: Paroxysmal nocturnal haemoglobinuria: diagnostic tests, advantages, \& limitations. Eur J Haematol 2009, 83:503-511.

10. Kwaan HC: Infection and anemia. Infect Disord Drug Targets 2011, 11:40-44.

11. Yasouka C, Yasuoka A, Yamamoto Y, Genka I, Hatabu T, Kohno S, Oka S, Kano S: A case of falciparum malaria successfully treated with intravenous artesunate. Kansenshogaku Zasshi 2001, 75:822-825.

12. Yoshizawa S, Hike K, Kimura K, Matsumoto T, Furuya N, Takeda K, Kano S, Yamaguchi K: A case of falciparum malaria successfully treated with intravenous artesunate. Kansenshogaku Zasshi 2002, 76:888-892.

13. Itoda I, Yasunami T, Kikuki K, Yamaura H, Totsuka K, Yoshinaga K, Teramura M, Mizoguchi H, Hatabu T, Kano S: Severe falciparum malaria with prolonged haemolytic anemia after successful treatment with intravenous artesunate. Kansenshogaku Zasshi 2002, 76:600-603.

14. Zoller T, Junghanss T, Kapaun A, Gjørup I, Richter J, Hugo-Persson M, Mørch K, Foroutan B, Suttorp N, Yürek S, Flick H: Intravenous artesunate for severe malaria in travelers, Europe. Emerg Infect Dis 2011, 17:771-777.

doi:10.1186/1475-2875-11-91

Cite this article as: Corpolongo et al: Haemolytic anaemia in an HIV infected patient with severe falciparum malaria after treatment with oral artemether-lumefantrine. Malaria Journal 2012 11:91.

\section{Submit your next manuscript to BioMed Central and take full advantage of:}

- Convenient online submission

- Thorough peer review

- No space constraints or color figure charges

- Immediate publication on acceptance

- Inclusion in PubMed, CAS, Scopus and Google Scholar

- Research which is freely available for redistribution

Submit your manuscript at www.biomedcentral.com/submit 